\title{
Carnivalesque, Liminality and Social Drama: Characterising the Anti-Structural Potential of Theyyam
}

\author{
Raisun Mathew ${ }^{1} \&$ Dr Digvijay Pandya ${ }^{2}$ \\ ${ }^{1}$ Doctoral Research Scholar, Department of English, Lovely Professional University, Punjab, India, \\ Email: raisunmathew@gmail.com, orcid.org/0000-0003-3427-0941 \\ ${ }^{2}$ Associate Professor and Research Supervisor, Department of English, Lovely Professional \\ University, Punjab, India, Email: digvijay.24354@lpu.co.in, orcid.org/0000-0002-5985-9579
}

\begin{abstract}
The cultural and ritual performance of Theyyam in Northern Kerala, considered as a reflection of the war cry against the caste system and oppression, conducts subversion of the social hierarchy. The chosen deity by the performer for a transitory symbolisation expresses the collective outrage of the oppressed and exploited people. This research paper enquires about the anti-structural characteristics exhibited by the performance of Theyyam. In the context of Richard Schechner's performance theory, it attempts to trace the characterisation of Mikhail Bakhtin's carnivalesque, Victor Turner's liminality and social drama in the transitional performance of Theyyam that mostly relies on interim separation and reintegration. The expression of antipathy to the hierarchy in Bakhtinian carnival, the anti-structural emphasis in Turnarian liminality, and the deconstructive-reconstructive stages in social drama elucidate the symbolic delineation of the performance of Theyyam. The analytical findings of the paper derived from the discussion of the three concepts reveal that the performance of Theyyam is rooted in its anti-structural characteristics. The performer is subject to continuous alteration in the identity that intermediates the idiosyncrasy between the deity and the human being. It symbolises the temporal transition from the oppressed to the equivalent status of the dominator that occurs as part of counter-culture, through status reversal and inversion.
\end{abstract}

Keywords: carnivalesque, liminality, performance studies, social drama, Theyyam.

\section{Introduction}

The artistic and cultural performances that exist as an influential tool of resistance and protest against inequitable social system produce aesthetic pleasure and behave as reminiscences or impressions of the still prevailing struggle against the differentiation in the society. The intensely coloured and dynamically vibrant actions of the religious rituals and festivals have always enhanced the sacred beliefs and cultural affiliation of communities. Performance studies, which actively involves the study of artistic practice, behaviour, participant observation and active involvement in social practices (Schechner, 2013, p. 2), has always been conscious expressive methods of culture. Likewise, its dialectic nature voices the uniqueness of specific cultures and 
declares the common shared humanity (Schechner and Appel, 1990, p. 1). The embodiment of performances that affirm the bondage between culture and social situations produces much powerful expression of repressed emotions invoking factual reality through artistic representations.

Caste inequalities and untouchability that proliferated in the Northern region of Kerala (India) have resulted in the gradual emergence of a performance that influenced people in the lower spheres of the society. The blend of art, dance, music, culture and religious beliefs associated with Theyyam, also known as the dance of Gods, beyond the aesthetic aspect of its performance, have invited the academic interest of scholars to analyse its peculiar features, historical and cultural associations with erstwhile and contemporary social living. Having around four hundred varieties and a tradition of more than a thousand years, the pantheistic art form is rooted in the myths of animate subjects of reference such as trees, plants, serpents and animals in the form of spirited dance and songs. The diversified myths and visual elements incorporated in the performance of Theyyam locate its presence over certain areas of Kozhikode, Kannur and Kasaragod districts in the state of Kerala. Closely related with the lower caste Hindus of Chunkathan, Karimban, Mayilon, Munnutton, Malayan, Vannan, Anhuttan, Kuppalan and Pulayan, the ritual centric performance takes place in the shrines or what is known locally as kavu (Nambiar, 2007, p. 44-45). Possessing an outlook of sacredness connected with religious devotion, the experience of the participants is more inclined to the ritualistic aspect than towards its artistic excellence. Some of the most popular active forms of Theyyams performed are Vaishnava, Pottan, Theechamundi, Manakkott Amaa, Kuttichathan, and Chamundi.

The three conceptual perspectives selected to examine the structural pattern of the Theyyam performance are the Russian literary critic Mikhail Bakhtin's [1] carnivalesque, the British cultural anthropologist Victor Turner's [2] liminality and [3] social drama. Carnivalesque is the upside-down reversal of rules and positions, denoting suspension of the normative forms of hierarchy in society. It provides immense freedom and a feel of equality as part of the inversion of official values and social rules. A similar perspective is shared by the British cultural anthropologist Victor Turner in describing the egalitarian concept of communitas referred to in the essay "Liminal and Communitas" (1969) that introduces the different attributes of liminality as part of his study on rituals in selected tribal communities. Inspired and influenced by the concept of rites of passage by Arnold van Gennep, the elaborate discussion of liminality by Turner led to the theoretical perspectives of social drama. The symbolism of breach and crisis resolution among the tribal villagers described the sequence of social interactions associated with the dynamic processual approach. The analytical insights derived from the three theoretical concepts converge to provide the thesis statement that the performance of Theyyam is embedded in its antistructural characteristics. The term 'anti-structure' denotes the deviation from normality, order, hierarchy, authority and different cognitive aspects of organised human society (Tutt, 2015). Unlike social structure, it presents an unusual diversion from the already set rules or traditional attributes. Thus, it takes the position of opposing the identity and structural existence of someone/something.

\section{Existing Research on Theyyam. Review of Literature}


Considering the prerequisite significance of the theoretical framework to the research, the existing scholarship related to Theyyam performance helps to identify the potentiality of research based on the three selected conceptual perspectives. In Schechner's and Turner's concept, performance is considered to be liminal, denoting a creative, liberated and purely potent activity (Shepherd, 2016, p. 45). Though celebrated as a local ritualistic observance, the artistic and performative brilliance of Theyyam has invited global attention from aesthetic and academic viewpoints. The contemporary regional identity of Theyyam has been widened with the intervention of recent developments, media and technologies. The changing social, religious and cultural scenarios have created substantial alterations in the physical domains of the performance including the number of protected sacred groves (de Martino, 2016).

Similar to the diverse ritualistic performances, the sacred invocation of Theyyam's transformational character acts as a community preserver offering a therapeutic process. It exhibits itself as "an expressive space for lower-caste people, who in the performance, are symbolically transformed into dual, human-god" (Madathil, 2021, p. 162). The existing harsh realities of caste inequalities, economic exploitation and inhumane societal discrimination are revealed through the performance (Gopi, 2021) in which it becomes a tool of criticism and protest. Researchers have explored the roots of the origin of Theyyam, pointing to the collective victimhood and caste-based oppression in the Northern parts of Kerala. The psycho-cultural phenomenon of the repressed trauma reaction and its healing process through Theyyam is addressed through such studies discovering the symbolic meaning of Theyyam as empowerment, dissent and protest. The characteristics of ritual inversion, the reflection of social processes and social catharsis in Theyyam exposes the injustices and terror imposed by the upper castes on the community, thus "helping people cope and heal from traumatising experiences" (Ahammed, 2019, p. 99-100).

From the ethnographic perspective, the dynamics of Theyyam performance develops a specific cultural and regional identity among the Keralites in the Indian diaspora. Its significance on the historical, cultural, traditional and religious aspects produces a transnational identity (Sahoo and Surabhi, 2021). This can be extended to resolve the social and financial instabilities of the local people through effective administrative policies. The aestheticism and potentiality for tourism of the art form can reduce and eliminate the suppression by empowering the marginalised communities (John, 2015). The connection between paraphernalia of Theyyam with nature in light of the concept of eco-fear and ecophobia is used to examine the influence of fear in people. The myths related to the performance art as a ritual process is explained through the fear theories proposed by R. M Fisher. It states that the ritual art performance provides a ray of hope developing resilience by maintaining its love for nature (Sankar, 2001, p. 114). The practice of untouchability by the higher castes restrained the lower castes from entering the temples. Theyyam became a counter-reaction to the system as it is performed at the home courtyards and sacred groves of the lower castes resembling the Brahmanical temple ceremonies (Freeman, 1988, p. 83; Pereira, 2021). These insights support and substantiate the present research that concentrates on the formation of counter-culture, communitas and anti-structure exhibited through the performance.

The purpose of this research paper is to examine the characterisation of Mikhail Bakhtin's carnival sense of the world often termed as Bakhtinian carnivalesque, the anti-structural aspects 
of liminality and the deconstructive-reconstructive stages of social drama by Victor Turner on the ritual-oriented performance of Theyyam. The argument that emphasises the presence of carnivalesque, liminality and social drama in such a dialectic performance is substantiated through the application of the rites of passage in its structural pattern that relies on the interim separation and reintegration. From the analysis of the review of literature, it imparts that there has been no specific research on the anti-structural aspect of Theyyam utilising the three conceptual perspectives. Secondary sources that contain authentic information about the performance, critical perspectives of scholars and analytical findings have been incorporated to gradually develop and thereby substantiate the argument of the paper.

\section{Theyyam or the Dance of Gods: The Ritual Theatre of Northern Kerala}

The elevation of the performer to the status of deity is the core of Theyyam that is based on the ritualistic form of worshipping gods, goddesses, and even animals. The concept behind Theyyam is that the person performing it gets empowered, and his body is manifested by the god or goddesses. Thus, the status of the performer gets elevated wherein he represents the figure of the worshipping deity.

The display of grotesqueness (Dentith, 1995, p. 51) and the absence of borders between the performer and audience described by Bakhtin (Kristeva, 1982, p. 53) resemble the artistic and ritualistic performance of Theyyam or Theyyattam. In the regional language, the word theyyam means God and 'aattam' denotes dance - together called the dance of Gods. Unlike the dance in other rituals to please Gods, Theyyam is considered as the dance that is performed by the Gods. The myths and stories become the backbone of Theyyam performances as one differs from the other ensuring uniqueness. These myths that are used as a backdrop of the performances are the direct and indirect expression of the social system of the past which continues to haunt the lower caste people in the area. Rather than narrating the traditional epics, it showcases common men and women who are through the ritualistic performance transformed to the status of deities. This concept of transformation during the performance symbolises the glorification of ordinary people and their social status. The deities represent the lower caste that continues to be exploited by the dominant groups in society. By providing a heroic identity to them, considering them as higher to the existing social system, and worshipping their existence as elevated, the performance situates itself with the downtrodden and the oppressed groups in the society. The history of Theyyam records that the transformed identity of the performer allows him to enter into a Brahmin's house even though he is otherwise considered as a lower caste untouchable. Rajesh Komath, a Theyyam practitioner says,

In those days when untouchability was prevalent, they were treated like untouchables. But when they performed Theyyam, they could be touched. People would fall at their feet and seek their blessings. And the moment he takes the costume off, he becomes an untouchable again.

(Varma, 2018)

The deity transformation of the performer appears before the devotees, who anxiously and fearfully wait for his arrival. The high-pitched drums, music, songs, and symbolic actions of the performer provide an ambience of devotional sacredness. The collective voice of the unprivileged is reflected and resonated through the then transformed performer known to be the deity who 
dances several rounds around or through a fire setting that is considered sacred. However, versions of Theyyams like Pottan Theyyam represent "the features of liminality, lucidity, ritual inversion, social catharsis and reflection of social process" (Ahammed, 2019, p. 97). The celebration of Theyyam extends to a minimum of one sleepless night and is normally conducted between October and April.

\section{Discussion: Carnivalesque, Liminality and Social Drama}

Two seminal texts of Bakhtin namely, Problems of Dostoevsky's Poetics (1963) and Rabelais and His World (1965) contribute to the perspectives on carnival and carnivalesque. The counter-culture advocated through carnivalesque arrives from the idea of carnival that exhibited the double sphere of life wherein it created an alternate space that enabled abundant freedom and equality (Robinson, 2011). The experience of egalitarianism in such carnivals overturns the official and dominant hierarchical culture. An emphasis to showcase the repressed innateness of a human being is evident during carnivals. The festive modes of carnivals exercise undefined playfulness of voices (Bruke, 2004, p. 52) that possess no scope to express itself against the coercive attempts of the structural situations of life demanded by the sense of lowliness. The oxymoronic and cosmocentric model of interpretation that develops through such distinguishing polarity points to the observation that

the opposition between the unofficial culture of laughter and the official culture of order thus appears to be one between a culture of ambivalence and a culture of monovalence. (Lachmann et. al., 1988, p. 130)

Apart from the social and cultural status of individuals or groups, the middle phase of the rites of passage that denotes the liminal phase of transition marks their psychological state. Turner explains liminality as "a movement between fixed points that is essentially ambiguous, unsettled and unsettling" (Turner, 1974, p. 274). Unlike the temporal reversal of order, these fixed points denote the structural normality that follows the traditional and usual pattern of the lower caste as discriminated, marginalised and oppressed. The intermediary phase of transition from the preliminal to the post-liminal in an individual, produced as a result of the uncertainty, unusualness and ambiguity, is a process of detachment from "a previous world" (van Gennep, 1960, p. 21) and an "incorporation into the new world" (p. 21). It is also defined as a "detachment from the earlier fixed point in the social structure" (Turner, 1969, p. 47) to a newly formed reintegrated phase. This processual framework proposed by Victor Turner derives from Arnold van Gennep's tripartite structure introduced in Les Rites de Passage (1909). Discussing the concept of communitas under the framework of liminality, Turner expresses his views on the liminal phenomena that offer "lowliness, sacredness, homogeneity and comradeship" (Turner, 1970, p. 96).

Similar to the concept of liminality, Victor Turner utilises the processual framework to define the "volatile episodes of social action that erupt forth from the otherwise smooth surface of routine social life" (Turner, 1969, p. 9). They are considered to deconstruct and reform the existing social order by following the same 'structure - antistructure - structure' pattern described in the processual framework. The potential turning points of social drama resemble the separation from the pre-liminal and the reintegration into the post-liminal phase. If categorised, the deconstruction phase of the social drama can be identified with the stages of breach and crisis, and the reconstruction phase by redress and reintegration (Turner, 1974). 


\section{Analytical Interpretation}

\section{Counter-culture and Inversion}

In the attempt to define the structural peculiarity of the ritualistic and aesthetic performance of Theyyam, the insights shared in Bakhtin's carnivalesque, Turner's liminality and social drama converge to exhibit its anti-structural characteristics. The anti-structural aspect of Theyyam arises due to the essential nature of the performer who is considered to have a gradual shift in his identity. According to the pattern followed in the performance, the performer conducts a transition from his normative and permanent identity as a lower caste to the status of a deity and thereafter transits back to the original individuality.

Bakhtin's version of carnival laughter is a liberation that is temporary from the formal order and prevailing truth (Bakhtin, 1984, p. 10) that helps to break from the formal embodiments and barriers of hierarchy to play its altered roles (Clark and Holquist, 1984, p. 251). The same is expressed in Theyyam that deviates temporarily from the existing social norms of hierarchy, providing space for the lower-caste to express their freedom. The forms of grotesque that reveal the mutual existence of the low on the high and vice-versa in Bakhtin's carnivalesque (Hall, 1993, p. 8) reflects Theyyam's cultural and ritualistic attributes. The real-life projection of carnival devoid of a stage to present its inverse actions makes the participant both performer and spectator (Vice, 1997, p. 149). The wholesome participation of a group of people having ideological equivalence participates to celebrate the disappearance of their responsibilities and appearance of the mark of the carnival (Bakhtin, 1984, p. 95).

The intermediate phase applicable to Theyyam denotes the period of suspension of the social order (Thomassen, 2014, p. 92) and devoid of status for equal treatment (Deflem, 1991, p. 13-14). This process, which has a strong base in the ritualistic and performative facets of Theyyam is also regarded in the socio-cultural context as a temporal elevation from the status of a lower caste to the higher. The untouchability practice that was exercised by the higher caste on the lower is excused during this particular deity phase of the performer. Equivalence is subjected to the lower caste performer by the higher caste, which even extends to the traditional practice of receiving prasadam from the deity-turned-performer. It is a part of the ritual status-reversal where Theyyams "abuse, revile and even physically maltreat the highest authority with unusual aggressive temper" (Pallath, 1999, p. 55). This interpretation derives from the counter-culture and inversions proposed by Bakhtin in his insights on carnival and carnivalesque.

Thus, the carnival and carnivalesque discovered by Bakhtin turns out to be an existence different from the previous lower strata to an altered sense of liberty. This is also experienced during the intermediary phase of Theyyam where it unmasks the hidden individuality of the person to express it to the utmost purity and volition.

\section{Homogeneity, Anti-Structure and Elevation of Status}

From the perspective of the concept of communitas that points at the egalitarianism and comradeship of the ritual participants denoting homogeneity (Turner, 1969, p. 96), the deity phase where the status of the performer is elevated is considered as a symbolic representation of the 
lower caste people. The performer's existence thus becomes "neither this-nor-that, here-northere, one-thing-not-the-other" (Turner, 1977, p. 37). This occurs from the instability possessed due to the transition from one to the other status - not innately a higher caste, not presently a lower caste and not permanently a deity. The lower castes, same as in the carnivals, experience freedom and relief from their oppressed identity. This liberty allows Theyyams to directly and indirectly attack social oppression, exploitation and discrimination that eventually leads to satisfaction and relief in the unprivileged people (Damodaran, 2009, p. 195).

The moving in and out of the process of time during Theyyam depends on the two major models proposed by Turner based on the ritual transitions. The first is about the differentiated, structured and frequent hierarchical system that distinguishes and discriminates people on the basis of their status and the second is "unstructured or rudimentarily structured and relatively undifferentiated comitatus, community or even communion of equal individuals" (Turner, 1970, p. 96). Theyyam's concept exhibits the combination of the two models where the second becomes the intermediary temporal phase of acquiring the deity status. The sacredness and holiness of the rituals that practices reversal of order and inclusion of humans irrespective of hierarchy (p. 104), "transgresses or dissolves the norms that govern the structured and institutionalised relationships" (Turner, 1970, p. 128).

The anti-structural characteristic of liminality often produces inversions and reversals in an established structure that asserts the significance of communitas (Gluckman and Gluckman, 1977, p. 242). In societies, the situation of discrimination and marginalisation occurs where there exists the domination of the upper strata over the lower. This process of denial, silencing and elimination divides the community into many layers according to their societal status. The performative and ritualistic characteristic of Theyyam acts as a counter-reaction to this notion. The process of inversion of these gradually normalised societal traditions and rules is termed as 'liminalisation of marginality' or the re-valorisation of marginal in which the outcast status is expressed as the only authentic and genuine human condition (Szakolczai, 2000, p. 184). Thus, it can be identified that the marginalisation of the lower caste does not occur during the period of liminality (deity stage) that has the intermediary status in the ritual performance.

Though there are only a few selected people to assist the Theyyam performer, the vast number of devotees who attend the celebration merge to the spiritual, ritualistic and performative ambience created by dance, songs and vibrant costumes. Therefore, aesthetic, ritualistic and socio-cultural communitas is formed as a result of the transitional attribute of the performance of Theyyam. These observations combine to state that rituals such as the performance of Theyyam are "collective memories encoded into actions" (Schechner, 2002, p. 52). Thus, it reveals that the rituals also help people deal with difficult transitions, ambivalent relationships, hierarchies, and desires that trouble, exceed, or violate the norms of daily life.

(p. 52)

\section{Reversal of Status and Transition}

The majority of the performances, especially those that are based on narrative plots having incorporation of dance, music and action, include the mechanisms for transformation (Schechner, 1990, p. 170) either from the perspective of the performer or the spectators. While analysing the structural pattern of the performance along with the ritualistic beliefs as mentioned earlier, the 
Theyyam performer transits from his normative status (lower caste human) to the identity of the deity performed (reversal of status) and then reintegrate into his actual identity. This process highlights the breach from the normative ideologies possessed by the society about them by evoking a crisis in the structural system to reconstruct their status and identity through the phase of redressal. It denotes the initiation of the procedures to Theyyam performance that moves onto the intermediary phase of elevation in status and then back to normality. The demobilising characteristic of the breach to introduce the new ideological standpoint alters the flow in order to inverse the current social order. The equality possessed symbolically by the lower castes through Theyyam as a denial of the existing hierarchical system is enjoyed for the temporary period. Towards the end of the processual framework that guides the social drama, the performer reintegrates the situation or identify the state of dissonance present between the opposite groups or ideologies (Turner, 1974, p. 41-42).

Here, the earlier mentioned reversal, inversion, elevation, counter-culture and egalitarianism occurs in the performer who indirectly represents the lower caste people. The challenge raised by the lower caste on the higher that liberates them from the existing social structure is neutralised by considering the religious and ritualistic identity of Theyyam. Based on this perspective, the open theatrical performance can be located "as a way to experiment, act out and ratify change" (Schechner, 1983, p. 170).

\section{Conclusion}

The research paper discussed whether the ritualistic performance of Theyyam resembles the characteristics expressed by Bakhtin's carnivalesque, Turner's liminality and social drama. The analysis provided essential information on the status reversals, inversions and counter-culture of Theyyam. The thesis statement that the performance of Theyyam is rooted in its anti-structural characteristic gradually gets substantiated through the findings and discussion of the insights derived from the three theoretical concepts. The peculiarities of carnival and carnivalesque, liminality and communitas, and social drama resemble its effects on the performance of Theyyam through the performer, its ambience and the ritualistic beliefs of the spectators. The significance of the research based on Theyyam, beyond its performative status, lies in its shared social, cultural, aesthetic and ritualistic aspects. While the social and cultural aspect of Theyyam relates with the lower caste-upper caste hierarchical differentiation countered through the performance, the aesthetic and ritualistic facet is attached with Theyyam as a performance and ritual practice of the North Malabar region in the state of Kerala located in India.

The anti-structural characteristic of Theyyam emphasises the revolutionary freedom possessed to counter the existing attitude on the status of the lower caste. The attribution of the quality of alterity in the performer during the reversal and inversion of status exhibits the antistructural pattern followed in the performance. Therefore, the performance of Theyyam is closely attached to the lower caste for evoking their unfortunate memories of being oppressed by the higher caste, finding reliefs and solutions to their problems of the past and present, and thereby considering themselves to have equal status same as that of the upper caste.

\section{References}



of Theyyam

Ahammed, S. (2019). Caste-based Oppression, Trauma and Collective Victimhood in Erstwhile South India: The Collective Therapeutic Potential of Theyyam. Psychology and Developing Societies, 31(1), 88 105. https://doi.org/10.1177/0971333618825051

Bakhtin, M. (1984). Rabelais and his World (H. Iswolsky, Trans.). Indiana University Press. (Original work published 1940).

Bruke, P. (2004). What is Cultural History?. Polity Press.

Clark, K., \& Holquist, M. (1984). Mikhail Bakhtin. Harvard University Press.

Damodaran, M. P. (2009). Identity through Nature-Man Interaction: A Synthetic Definition Based on the Teyyam Performance in North Malabar. Journal of Human Ecology, 26(3), 191-196. https://doi.org/10.1080/09709274.2009.11906181

Deflem, M. (1991). Ritual, Anti-Structure and Religion: A Discussion of Victor Turner's Processual Symbolic Analysis. Journal of the Scientific Study of Religion, 30 (1), 1-25. JSTOR, http://www.jstor.com/stable/1387146

de Martino, G. (2016). Between Local and Global. Cracow Indological Studies, 18, 23-54. https://doi.org/10.12797/CIS.18.2016.18.03

Dentith, S. (1995). Bakhtinian Thought: An Introductory Reader. Routledge.

Freeman, J. R. (1988). Formalised Possession Among the Tantris and Teyyams of Malabar. South Asia Research, 18 (1), 73-98. https://doi.org/10.1177/026272809801800104

Gluckman, M., \& Gluckman, M. (1977). On Drama and Games and Athletic Contests. In S. F. Moore \& B. G. Myerhoff (Eds.), Secular Ritual (pp. 227-43). Van Gorcum.

Gopi, A. (2021). Gods and the Oppressed: A Study on Theyyam Performers of North Malabar. Contemporary Voice of Dalit. https://doi.org/10.1177/2455328X211008363

Hall, S. (1993). Metaphors of Transformation. In J. Barrell, J. Rose, P. Stallybrass \& J. White (Eds.), Carnival, Hysteria and Writing (pp. 1-25). Oxford University Press.

John, J. (2005). Dalit Art Forms and Tourism Promotion: Case Study of Theyyam Dance. Atna Journal of Tourism Studies, 10(2), 1-15. https://doi.org/10.12727/ajts.14.1

Kristeva, J. (1982). Powers of Horror: An Essay on Abjection (L. S. Roudiez, Trans.). Columbia University Press.

Lachmann, R., Eshelman, R., \& Davis, M. (1988). Bakhtin and Carnival: Culture as Counter-Culture. Cultural Critique, (11), 115-152. https://doi.org/10.2307/1354246

Madathil, S. (2021). Ritual, Community Preservation, and Environment in Theyyam Performance. Ecumenica, 14 (1), https://doi.org/10.5325/ecumenica.14.1.0162

Nambiar, A. K. (2007, January). Theyyam: Ritual Theatre of North Malabar. Kerala Calling, 44-45. https://kerala.gov.in/documents/10180/1b2d7ecb-d957-465a-9a2c-c3041fa63f38

Pallath, J. J. (1999). Subaltern Christian Groups and the Crisis of Cultural Identity: A Case Study of Christian Pulaya of North Kerala. Journal of Dharma, XXIV (1), 55-66. https://www.dvkjournals.in/index.php/jd/article/download/859/738

Pereira, F. (2021). Does Faith Dismiss Performance? Observations on the Cult of Muthappan in Northern Kerala. Ecumenica, 14(1), 127-138. https://doi.org/10.5325/ecumenica.14.1.0127

Robinson, A. (2011, September 9). In Theory Bakhtin: Carnival Against Capital, Carnival Against Power. Ceasefire, https://ceasefiremagazine.co.uk/in-theory-bakhtin-2 
Sahoo, A. K., \& Surabhi, K. (2020). Diaspora, Religion, and Identity: The Case of Theyyam in the Indian Diaspora. Asian Ethnicity, 1-18. https://doi.org/10.1080/14631369.2020.1737506

Sankar A. R. (2021). An Analysis of Reverential Ecofear in Theyyam: A Ritualistic Performance of NorthMalabar. International Journal of Fear Studies, 3(1), 105-15. http://hdl.handle.net/ 1880/113235

Schechner, R., \& Appel, W. (1990). By Means of Performance: Intercultural Studies of Theatre and Ritual, Cambridge University Press.

Schechner, R. (1983). Essays on Performance Theory 1970-1976. Drama Book Specialists.

Schechner, R. (2002). Performance Studies: An Introduction. Routledge. (Original work published 1934).

Schechner, R. (2013). What is Performance Studies?. Special Issue on Performance Studies [Special Issue]. Rupkatha Journal of Interdisciplinary Studies in Humanities, 5(2), 2-11. http://rupkatha.com/V5/n2/02_What_is_Performance_Studies_Richard_Schechner.pdf

Shepherd, S. (2016). Cultural Performance, Social Drama and Liminality. In The Cambridge Introduction to Performance Theory (Cambridge Introductions to Literature, pp. 42-46). Cambridge University Press. http://doi.org/10.1017/CBO9781139600194.006

Szakolczai, A. (2000). Reflexive Historical Sociology. Routledge.

Thomassen, B. (2014). Liminality and the Modern: Living Through the In-Between. Ashgate Publishing Limited.

Turner, V. (1969). The Ritual Process: Structure and Anti-Structure. Cornell University Press.

Turner, V. (1970). The Forest of Symbols: Aspects of Ndembu Ritual. Cornell University Press.

Turner, V. (1974). Dramas, Fields, and Metaphors: Symbolic Action in Human Society. Cornell University Press.

Turner, V. (1977). Variations on a Theme of Liminality. In S. F. Moore and B. G. Myerhoff (Eds.), Secular Ritual (pp. 36-52). Van Gorcum.

Tutt, D. (2015, March 20). Religion and Communitas: Structure and Anti-Structure. Danie/ Tutt. https://danieltutt.com/2015/03/20/religion-and-communitas-structure-and-anti-structure

Van Gennep, A. (1960). The Rites of Passage (M. Vizedom \& G. Caffee, Trans.). The University of Chicago Press. (Original work published 1909).

Varma, V. (2018, April 1). Theyyam: When the 'lower castes' Turn Gods and Goddesses. The Indian Express, https://indianexpress.com/article/lifestyle/art-and-culture/theyyam-when-the-untouchables-turngods-and-goddesses-5119449

Vice, S. (1997). Introducing Bakhtin. Manchester University Press.

Raisun Mathew is a Doctoral Research Scholar in the Department of English at Lovely Professional University, Punjab, India. He is the author of Zephyr: The Breeze of Love, editor of Literature, Media and Society: Scholarly Perspectives, and The Post-Truth Era: Literature and Media. Besides presenting research papers at international and national conferences, he serves as a resource person to deliver academic lectures and conduct workshops. He has several research papers in 
11 Carnivalesque, Liminality and Social Drama: Characterising the Anti-Structural Potential of Theyyam

scholarly journals, articles in The New Indian Express, also poems and short stories in magazines to his credit. His research and publication interests include American literature, liminality, posttruth, medical humanities, translation and religious studies.

Dr Digvijay Pandya is an Associate Professor in the Department of English at Lovely Professional University, Punjab, India. He has more than 17 years of teaching experience in the field and has presented and published several papers in various international and national conferences and reputed journals. His research interests include contemporary theories, linguistic studies, modern poetry, medical and digital humanities. 